\title{
The Entrepreneurship Education Courses' Setting of American Colleges and Universities and Its Enlightenment to China: A Case Study of Babson College
}

\author{
Li-zhen $\mathrm{JIN}^{1, a,{ }^{*}}$ and Yue-han YANG ${ }^{2}$ \\ ${ }^{1,2}$ College of Law and Politics, Tianjin University of Technology, Tianjin, China \\ ajinlizhen2006929@163.com
}

Keywords: American colleges and universities, Entrepreneurship education, Entrepreneurship course.

\begin{abstract}
The United States is the first country to carry out entrepreneurship education. Improving the curriculum is the key to the development of entrepreneurship education. Babson College is the well-deserved leaders of entrepreneurship education in colleges and universities. It has formed the perfect entrepreneurship education curriculum system. Babson College is the basic paradigm of entrepreneurship education courses in colleges and universities which leads the development of entrepreneurship education of the United States and even the whole world. Therefore, a case study of Babson College's entrepreneurship education curriculum system in colleges and universities and their Settings, has important reference and enlightenment to perfect the entrepreneurship education curriculum system for the colleges and universities of China.
\end{abstract}

\section{Introduction}

In November 1989, the United Nations educational, scientific and cultural organization was held in Beijing international symposium on "Education Facing the 21st Century", and "The Philosophy of Education in the 21st Century". The report put forward the concept of "Entrepreneur Spirit Education and Pioneering Spirit Education", which was translated into "Entrepreneurial Education" later. Entrepreneurship is regarded as "The Third Education Passport" which people should grasp in the future. The report also required to increase the entrepreneurship education's status equal to the current academic education and occupational education. Entrepreneurship education theory was researched and practiced firstly in the United States. Babson College is the leader of entrepreneurship education in colleges and universities. It is the basic paradigm of entrepreneurship education courses in colleges and universities, which leads the development of entrepreneurship education in the United States and even the world, worthy of our in-depth study.

\section{The Entrepreneurship Education Curriculum Settings of Babson College}

Babson College is famous for its "entrepreneurial culture". At Babson College, entrepreneurship is not only a discipline, it is also a way of life. Babson believes that entrepreneurship is a way of thinking, inference and action, its core is to create or to identify opportunities and the ability to seize the opportunity. Since it was established in 1919, entrepreneurship education is closely related to the development of the Babson College. Thanks to its founder, Roger Babson's outstanding vision of entrepreneurs, Babson each stage is deeply laid of the entrepreneurship education in its development of more than 90 years. In 1967, Babson provided the first 
entrepreneurship education courses for graduate students, which marked the development of entrepreneurship education, had entered a new stage.

\section{Progressive Undergraduate Entrepreneurship Education Courses}

Babson opened the entrepreneurship major in undergraduate phase in 1968, to provide comprehensive and integrated business courses for the students with entrepreneurial interests and potentials, in order to help students to form entrepreneurial thinking step by step. As the world's first undergraduate entrepreneurship major, it focus on opportunity identification, evaluation and implementation. Babson has the world's strongest entrepreneurship education teachers, including 12 specialized tenure professor and 22 entrepreneurs together with practice experience, so they can provide students with the academic philosophy and phase equilibrium of entrepreneurship education in real life experience. Perfect curriculum is the key to entrepreneurial education development. One of the Babson entrepreneurship education experts, Jeffry A. Timmons, who was known as the "father" of American entrepreneurship education, developed a creative, full of entrepreneurship education curriculum system. The curriculum system help to provide students with a broad range of both business knowledge and skills, and help students to success in the specific business system customized special path, such as the establishment of new enterprises, franchise, corporate entrepreneurship, social entrepreneurship and family business. According to different learning stages, Babson provide progressive entrepreneurship education programs. According to statistics, about $25 \%$ of the undergraduate degree was awarded the entrepreneurship in Babson each year.

FME: Management and Business Foundation Courses. FME are one-year interdisciplinary entrepreneurship courses which all new students must attend. Its core is characterized by simultaneous entrepreneurship theory learning and business practices. On the one hand, Babson provide students with economic theory, probability theory and statistics analysis, quantitative method and the company law and other related knowledge; On the other hand, students must learn investment, development, founding, management, an enterprise and learning at the end of the liquidation according to the learning theory of entrepreneurial teams. Babson provide each team up to $\$ 3000$ in start-up capital, in order to help enterprises' development in the early, and the entrepreneurial teams put the ultimate profit all donate to the "Community Service Plan".

ACE: Entrepreneurship Training Intensive Courses. ACE are the Babson's strengthen entrepreneurship courses which were set up in 2001. It is aimed at students with a high business potential in the second grade. Through intensive study, students can better understand what are "to be entrepreneurs", "how to evaluate and investigate new business opportunities", and "how to prepare a business plan". At Babson, a strong entrepreneurial motivation of the students has the opportunity to contact with all sorts of entrepreneurial activity in the early years of college. Through the training, students can master an important principle of entrepreneurship to make sufficient preparations for future business career.

Entrepreneurial Learning Custom Path for Senior Students. Babson has designed 10 elective courses and completed the core courses for senior undergraduate, including family business entrepreneurship, social entrepreneurship management, raise funds and real-time case studies, etc. Students can choose courses including new ventures, family business, the company business or social entrepreneurship four special areas according to their own interest in entrepreneurship to continue to deepen 
the study. Through these interdisciplinary course of study, a senior undergraduate students would deepen the understanding of entrepreneurship.

\section{Module Teaching Entrepreneurship Education Program of MBA}

Since 1993, Babson regarded entrepreneurship as the core of MBA education. By providing all full-time MBA students with courses to cultivate their comprehensive, integrated, entrepreneurship, entrepreneurial way of thinking, to identify the business cycle.

Courses based on Module. MBA entrepreneurship curriculum of Babson is composed of four integration module and 22 courses. Among these courses, the module 1 is for "a dynamic organization of creative management", the module 2 for "the business opportunity evaluation", module 3 for "messaging system design and management", module 4 for "the development company in global changing environment ". Each module is composed of a series of courses, the courses are known as the courses of all largest top MBA programs in the United States. Babson entrepreneurship courses are divided into three categories: (1) basic level (foundation classes) : in a global perspective to teach basic business skills, to all students interested in entrepreneurship; (2) professional (specialty classes) : according to the different subjects of entrepreneurship, to provide more in-depth knowledge of entrepreneurial skills; (3) support level (support classes) : specifically for a particular field of entrepreneurial learning, offering an in-depth business knowledge and skills. Due to the extensive business courses, about $90 \%$ of MBA students can complete the basic level in all subjects before graduation, including writing a complete business plan; More than $63 \%$ of the students continue to learn professional level and support level.

EIT: Project of the Entrepreneurship Improved Path. EIT provide students with a comprehensive business training in order to help students find the best market opportunities, and significantly increased second-year MBA students entrepreneurial skills. MBA students in the completion of the first year of study apply to the EIT. Applicants must provide their proposed business plan in detail, including industry and value chain analysis and so on. The judges according to the students candid selfexamination and self-discovery, inspects each student really have the needed intelligence, ability, tenacity and passion, to the student to carry on the strict screening, generally accepted 25-30 people each year.

EIT courses are highly centralized, the purpose is to cultivate students to put ideas into practice the necessary skills. Course consists of the complete module, each study term is about one year (from the May to the second year in May). Project full of flexibility enables the EIT to meet the special needs of each student and help them adapt to their best market opportunities, and ensure that they can obtain funds in the second year of the MBA program, set up their own businesses.

In addition to the complete theoretical study, EIT all module also contains specific practice content. Giving students with the chance to communicate with business experts, and encouraging students to use entrepreneurship knowledge into practice. Student is equivalent to have the composed of experienced consultants think-tank by communicating with potential investors, often experienced entrepreneurs and service personnel. At the same time, under the influence of Babson's entrepreneurship culture, EIT students can also participate in various group activities to foster unity cooperation ability. The coherence activities will combine classroom education and the improvement of the students' creative and transformation, to help students entrepreneurial success. 


\section{The Second Classroom}

Babson has a strong business atmosphere. In order to achieve the "immersion" entrepreneurship education teaching effect, Babson organization has conducted a diversity of the second classroom entrepreneurship practice activities. These activities almost cover all aspects of business activities, in order to create a good business atmosphere for students.

Business Hall of Fame: Build a Communication Platform for Students and Entrepreneurs. In 1978, Babson founded the world's first business hall of fame, to reward those entrepreneurs who had made outstanding contribution to the development of entrepreneurs around the world. These entrepreneurs were taking an active part in Babson entrepreneurship activities, such as a Babson business plan contest judge, and build communication platform of students and entrepreneurs.

The Business Plan Competition: To Encourage Students to Put Ideas into Business Practice. Babson's undergraduate and graduate students respectively participate in "John Mahler undergraduate business plan competition" and "Douglas foundation graduate business plan competition. The competition emphasizing the feasibility of the business plan, inviting contact entrepreneurs, venture capitalists, alumni of the jury, and designing feedback and suggestions for entrepreneurship students.

The Incubator: Incubate Students' Creativity. Babson has two hatcheries at both the undergraduate and graduate levels. The hatcheries provide the student with professional workplace, where they can set up and run their own company. It has created a team between teachers and students, where managers and entrepreneurs can share ideas and information under the atmosphere.

The Think-tank: Provide Entrepreneurial Guidance. The Think-tank was composed of outstanding entrepreneurs, venture capitalists, law, finance, management and accounting experts. It provides students with entrepreneurial intention counseling and guidance, helps students to solve the problem, put forward suggestions, and help the students to develop ideas, to determine the business model and strategy.

\section{The Enlightenment to China}

\section{Clear the Concept and Positioning of Entrepreneurship Education}

By studying the concept of entrepreneurship curriculum, it can be seen that the entrepreneurship education of the United States is based on the reality of a country needs and its long-term goal. The curriculum involves the entrepreneurial skills, entrepreneurial quality and entrepreneurial culture; The applicable objects involving all students rather than just school of business and management college students. In Chinese colleges and universities, their positioning is not clear at present, the schools entrepreneurship education curriculum goal is unclear, which leading to difficult to highlight the role of entrepreneurship education and value. Entrepreneurship education is not only a kind of ability or skill, it is more important to foster an innovative entrepreneurial spirit culture and value pursuit. In order to promote the success of entrepreneurship education in colleges and universities to carry out, we must establish a scientific concept of entrepreneurship education and reasonable entrepreneurship education targets.

Firstly, the government should formulate guidelines and policies basing on scientific and rational concept of entrepreneurship education. Secondly, colleges and universities should establish a reasonable concept of entrepreneurship education and 
curriculum goals, increase the importance of entrepreneurship education, optimize the integration of policy, fund, and the construction of teachers, curriculum and curriculum management and so on. Finally, parents, students and society from all walks of life should also set up the correct concept of entrepreneurship education. Entrepreneurship education is a higher level of quality education in the new period. We should regard enhancing personal comprehensive quality as the goal, break through the narrow understanding of entrepreneurship education, seize the good opportunity of the entrepreneurship education in developed countries actively, and be effort to implement entrepreneurship education ontology value and social value of the organic unity.

\section{Diversity of Entrepreneurship Education Curriculum}

Establish Multi-level Entrepreneurship Education Courses. Because of the difference in personal experiences, knowledge background and growth environment between all students and the difference between the undergraduate and graduate students of knowledge reserve level, their content needs of entrepreneurship is different, too. American colleges and universities have various types of entrepreneurship according to different students, and China should also make different levels of students in the emphasis of developing multiple entrepreneurship, so that the students can take what they need according to their own reserves of knowledge and the ability they have.

Set up Specialty Courses in Colleges and Universities. The development of entrepreneurship education curriculum is influenced by many factors, such as national entrepreneurship education policy, industry and regional economic development situation, school's educational philosophy, discipline construction, faculty, scientific research strength and other factors. Therefore, the colleges and universities must make full use of its resource advantage and face-to-face features to avoid weak factors, and help the development of high quality and unique entrepreneurship.

\section{The Entrepreneurship Education Curriculum Should Have Both Integrity and Discipline}

The Integrity of Entrepreneurship Education Curriculum. The key of entrepreneurship education curriculum is to cultivate the students' consciousness of entrepreneurship and innovation thinking. However, developing their awareness and innovation thinking is a process of accumulate over a long period. It is not only in the higher education stage by 3-4 years learning which can quickly be developed, it needs full of elementary education, secondary education, and is closely linked, mutual cooperation. Entrepreneurship education in the United States has achieved by the basic education stage to the cohesion of higher education stage, the diffusion degree is higher. And entrepreneurship education focused on the level of colleges and universities in China, so it is necessary to speed up the popularization of the entrepreneurship education curriculum, including basic education, undergraduate education, graduate education and on-the-job training, full entrepreneurship education curriculum system with Chinese characteristics. 
The Discipline of Entrepreneurship Education Curriculum. The United States has set up a professional entrepreneurship which can be conferred appropriate degrees. In addition, the United States established a large number of entrepreneurial academic journals to consolidate the leading position in the field of entrepreneurship research, which provides the entrepreneurship researchers with publishing a research platform, a large number of entrepreneurship scholars research for the development of the entrepreneurship. And the entrepreneurship education has provided important support. It is very necessary for entrepreneurship education in colleges and universities to use for reference the experience of the development of the United States, and consider the actual and features of our colleges and universities fully, strengthen the entrepreneurial education discipline construction and academic research, encourage academic research of the university and research institute for entrepreneurship.

\section{Organizing Curriculum Implementation in Different Ways}

Teaching is an important part of the curriculum implementation. The teaching means and methods of entrepreneurship education affect the entrepreneurship education curriculum implementation. Regarded as a new education idea, entrepreneurship education not only embodies the connotation of quality education, but also pays more attention to the cultivation of students' practical and innovative ability. The entrepreneurship education curriculum implementation in the current of China still given priority to teaching, students' practice is complementary, which neglects the subjectivity of students in entrepreneurship and entrepreneurship practice itself. With the gradually improving of China's entrepreneurship education courses, it is necessary to further explore the current class inside and outside development, emotional experience, business opportunity recognition simulation, the effective way to teaching methods, and further explore the multidimensional experience type teaching method through external organizational involvement and the cooperation with enterprises, such as the flexibility to use group discussion, case study, visit and project practice, industry simulation means to let the students actively participate in the each link of teaching entrepreneurship. On the other hand, expanding entrepreneurship education in the second classroom activity, using regional resources effectively, and strengthening the cooperation with enterprises and society are all important for the students to get more practice and exercise.

\section{Acknowledgement}

This research was financially supported by the Tianjin philosophy and social science research program (Project No.: TJJX16-005).

\section{References}

[1] Hui-min Sun, Gong-meng Chen. Global Innovation \& Entrepreneurship Education Research Report. Beijing: Economy \& Management Publishing House, 2016. (in Chinese)

[2] Katz, J.A. The chronology and intellectual trajectory of American entrepreneurship education 1876-1999. Journal of Business Venturing, 2003(18):283300 .

[3] Kuratko, D.F. The emergence of entrepreneurship education: Development, trends, and challenges. Entrepreneurship Theory and Practice, 2005, (9):577-597. 
[4] Zhan-ren Wang. The history of Innovative Entrepreneurship Education in China. Social Sciences Academic Press (China), 2016. (in Chinese)

[5] Yao Huang. A Study on Entrepreneurship Education in American Universities. Asia-Pacific Education (Chinese), 2016, (12): 185-186. (in Chinese)

[6] Chu-chu Xu. The Enlightenment of the Entrepreneurship Education in American Babson College to Chinese Colleges and Universities. Journal of Higher Education Finance (Chinese), 2016, 19(3): 15-18. (in Chinese) 